\title{
The role of herbal medicines in health care quality and the related challenges
}

\author{
Razieh Mirzaeian $^{1}{ }^{\circledR}$, Farahnaz Sadoughi $^{{ }^{*}}$, Shahram Tahmasebian ${ }^{3}$, Morteza Mojahedi $^{4}$ \\ ${ }^{1}$ Department of Health Information Management, School of Health Management and Information Sciences, Iran University of Medical Sciences, Tehran, \\ Iran \\ ${ }^{2}$ Health Management and Economics Research Center, School of Health Management and Information Sciences, Iran University of Medical Sciences, \\ Tehran, Iran \\ ${ }^{3}$ Department of Medical Biotechnology, School of Advanced Technologies, Shahrekord University of Medical Sciences, Shahrekord, Iran \\ ${ }^{4}$ Traditional Medicine and History of Medical Sciences Research Center, Health Research Institute, Babol University of Medical Sciences, Babol, Iran
}

\section{A R T I C L E I N F O}

Article Type:

Review

Article History:

Received: 23 July 2020

Accepted: 20 November 2020

\section{Keywords:}

Healthcare quality

Herbal medicine

Quality control

Herbal safety

\begin{abstract}
A B S T R A C T
In recent years, there has been a renewed interest in the use of herbal medicines. Quality control and safety are two critical principles to be considered in the production process of herbal medicines. This review study aimed to investigate the condition of the countries other than Iran in terms of observing the safety principles, quality control, and meeting the standard of herbal drug use. In this systematic review, references were selected using the search terms "health-care quality" and "challenges of herbal medicine usage" from the databases "Web of Science" and "PubMed" published between 2000 and 2019. To select the resources among the selected literature, confirmation was accomplished by two researchers and Cohen's kappa coefficient ( $\kappa)$. The selected papers were classified based on publication year, journal, country, reference standards, regulation, toxicity evaluation, quality control, efficacy, safety, and adverse effects in herbal medicine. From 1532 retrieved papers, 27 papers with an estimated Cohen's kappa coefficient of 0.81 were confirmed and included in the study. Based on the analysis, the main findings of the papers were thematically classified into seven subcategories as follows: reference standards in herbal medicine, regulation of herbal medicinal products, toxicity evaluation for herbal products, quality control of herbal medicine, efficacy, adverse effects of herbal medicine, and safety. Given the significance of the effects of herbal medicines on health care quality, it is essential to codify guidelines on the proper use of these drugs.
\end{abstract}

\section{Implication for health policy/practice/research/medical education:}

This review highlighted the importance of quality control and safety in herbal medicine by healthcare policy makers and increasing knowledge of people regarding their consumption.

Please cite this paper as: Mirzaeian R, Sadoughi F, Tahmasebian S, Mojahedi M. The role of herbal medicines in health care quality and the related challenges. J Herbmed Pharmacol. 2021;10(2):156-165. doi: 10.34172/jhp.2021.17.

\section{Introduction}

Herbal medicines are currently considered the oldest and most commonly used medical system worldwide (1). A large proportion of the population in developing and developed countries tend to rely on the herbal medicines for their primary healthcare. Based on the evidence, more than $90 \%$ of people in Africa, $70 \%$ in India, $70 \%$ in Germany, 48\% in Australia, 70\% in Canada, $42 \%$ in America, 39\% in Belgium, and 76\% in France meet their healthcare needs by using herbal medicines (2-6).

Herbal medicines are of high economic value. In the
United States, it takes an average of 12 years for a new synthetic drug from the research on and discovery of a new synthetic drug to market with a minimum cost of $\$ 230$ million. By comparison, the study and identification of herbal medicines require less time and cost (3). Based on estimations, the global herbal medicines market enjoyed an annual growth rate of over 15\% (7) and the global trade of herbal products is expected to reach $\$ 70$ million in the United States by 2050 (3).

As per the statistical reports, there has been a $31.7 \%$ increase in the volume of China's e-commerce market of 
herbal medicines in 2012 (8). The use of herbal medicines takes root to the traditional knowledge or the observation, and real experiences gained during the time. Plant-derived herbs interact with human biology (9); hence, quality control, safety insurance, proper usage, observance of reference standards, and efficacy are among the valuable components of herbal drug consumption (10).

In Germany, the usage of herbal medicines is regulated by the Healthcare \& Medical Organization. To ensure the herbal drugs' quality, safety, and effects, they are required to be produced in an environment known as good manufacturing practice (GMP). Until now, almost 380 papers on 360 plant species have been published to address this approach. In Canada, this approach has been supported by the preparation of a draft entitled "Guideline on the Quality of Herbal Medicinal Products" by the Committee on Herbal Medicinal Products (HMPC). This guideline lists the qualitative requirements for preparation of the herbal medicines in Canada and elucidates the required attributes, diagnosis and competency of the reference standards (11).

Despite the ever-increasing global acceptance of herbal medicine, cultivation of medicinal plants faces certain challenges. In other words, the industrial infrastructure of herbal medicines has not been given due consideration. Quality control and medicinal monitoring for the medicine's toxicity is poor. There is no monitoring of the herbal medicines' side effects and international standard describing the method and dosage of herbal medicines. Also, the people's knowledge about the complications of self-medication and the potential interactions of herbal medicines with chemical drugs is inadequate, and the proper and timely usage of the herbal medicines has not been given due attention. All these are among the challenges that may influence the effects of herbal medicines on health care (4).

In many European Union nations, herbal drugs are not covered by the health insurance; hence, many of these nations do not have any incentive to make investment or conduct clinical and non-clinical research in this field (12).

International Union of Practical and Abstract Chemistry (IUPAC) has issued some protocols on the quality, safety, control, efficiency, standardization, and documentation of herbal medicines. These protocols illuminate the important aspects of the chemical analysis of the herbs. If IUPAC fully implements these procedures, the World Health Organization (WHO) will start seeking out herbal medicines by adopting a new approach and would advance WHO Traditional Medicine Strategy 2014-2023 for the promotion of the complementary medicine and international industry of the herbal drugs production (13).

Iran is known as one of the oldest and richest nations in the field of herbal medicine. Due to the high acceptance of herbal medicines by the Iranians, the Ministry of Health and Medical Education has committed itself to promote the usage rate of these types of medicines in health care (14).

Over $80 \%$ of the popular and usable medicinal herbs are planted in Iran. Although herbal medicinal products play a significant role in Iran's economy as a significant component of its non-oil products exports, its RSCA index estimated by the Food \& Agriculture Organization in 1995-2008 was reported to be 0.93-0.83. Hence, Iran has shown a decreasing trend in comparison to the other six leading exporting nations of these products (15). The familiarity of all levels of health care providers with the herbal medicine capabilities is vital since it can assist health economics and promote the health care quality, provided that effective solutions can be developed for its potential challenges. This review study aimed to invest other countries' condition in terms of observing the safety principles, quality control, and meeting the standard of herbal drug use.

\section{Materials and Methods}

Study of the effects of herbal medicines consumption on health care quality and the related challenges across the world

This systematic review was done in accordance with the consistent guidelines of Preferred Reporting Items for Systematic Reviews (PRISMA) statement suggested by Moher et al (16). More clearly, we focused on wellformulated research questions to better understand the effects of herbal medicine use on healthcare quality. PRISMA methodology was implemented by the following five main steps: literature search, inclusion and exclusion criteria, study selection, quality assessment, and data extraction and synthesis.

\section{Literature search}

To identify the papers eligible for the study's purpose, a comprehensive search was done in the electronic databases of PubMed and Web of Science between 2000 and 2019. These databases provide a rich source of valuable and reliable information about the impact of herbal medicine on healthcare quality in different areas. In this step, references were selected using the search terms "herbal medicine", "herbal drug", "medicinal plants", "effectiveness", "safety", "evaluation”, "quality", "adverse effects", "efficacy", and "reference standard". A total of 1532 academic papers were identified. EndNote software was used to identify and delete the duplicate papers, and 797 papers remained for further analysis (Figure 1).

\section{Inclusion and exclusion criteria}

The original research papers with accessible full text in English and appearing in academic journals and international conferences were deemed as eligible for 


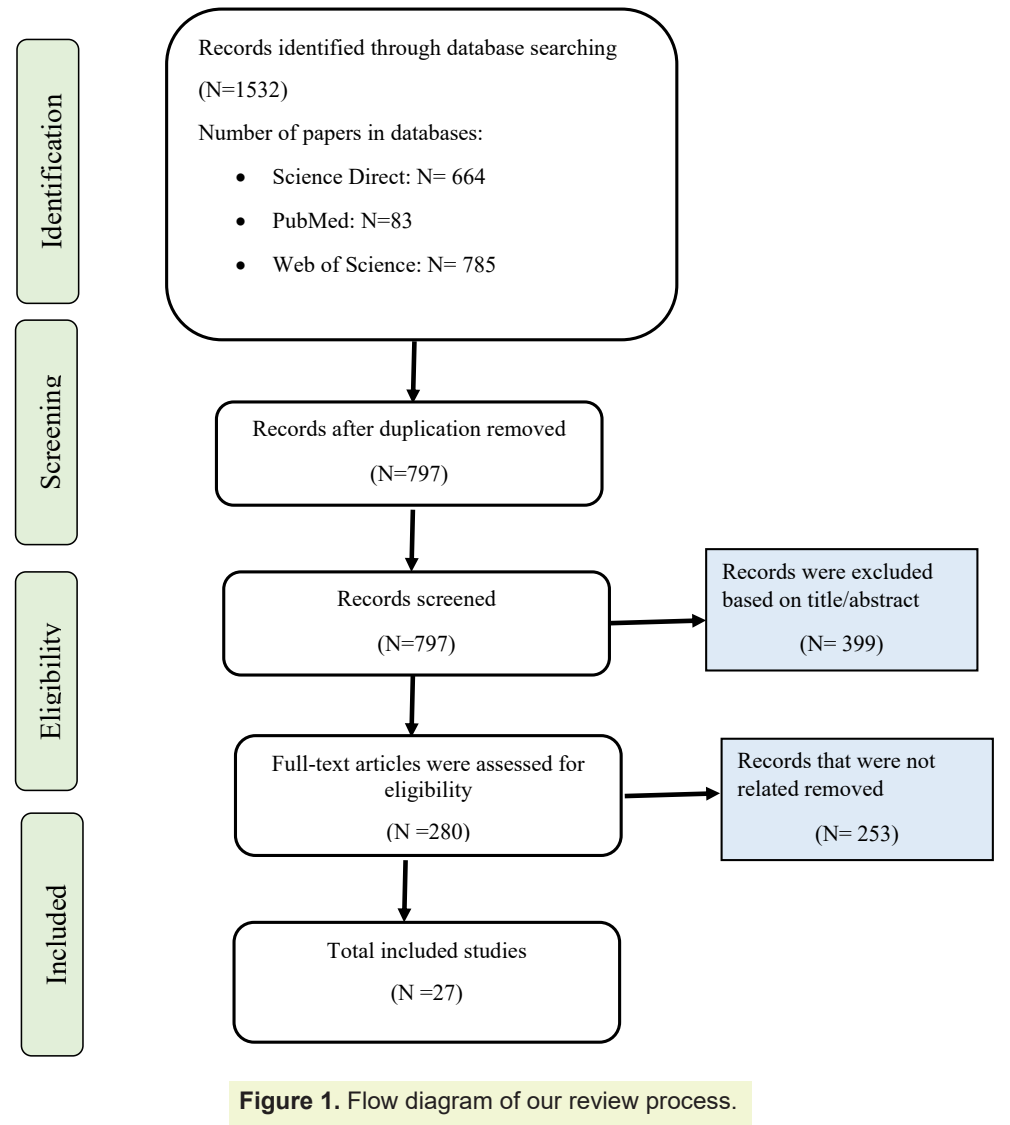

inclusion in the present study. The following research types were excluded from the study: reports, brief reports, reviews, editorial letters, case reports, case studies, perspective articles, symposiums, posters, brief communications, and commentaries, on-English papers, papers with only accessible abstract, and papers unrelated to the topic of the research or containing insufficient and vague information.

\section{Study selection}

The selection of the papers was carried out in two steps. First, two of the authors screened the papers independently in terms of titles and abstracts by considering the inclusion and exclusion criteria. In this way, all the irrelevant studies were deleted, and a total number of 280 potentially relevant papers remained. Secondly, to determine the eligibility of the selected papers, the authors independently reviewed the full texts of the papers selected in the previous stage. Finally, to reach a consensus, a careful step was taken to select the eligible papers. The foregoing steps resulted in the collection of 27 academic papers addressing the effects of herbal medicine on healthcare quality, their usage rates, and also challenges facing their usage (Figure 1).

\section{Quality assessment}

In this stage, the assessment of the quality of the selected studies was done by using the Mixed Methods Appraisal
Tool (MMAT) proposed by Pluye et al (16-18). To this end, two authors carefully studied the papers independently. In case of the agreement of two authors, the paper was selected and in case of lack of agreement, a third author was asked to judge. Furthermore, the rate of agreement between two authors regarding the confirmation of the selected papers was measured by the SPSS using the Cohen's kappa coefficient.

\section{Data extraction and synthesis}

In this step, an initial data extraction form was developed to draw the data elements from each paper. The collected data were then organized based on two sub-categories including general items (author, publication year, country/ state, study purpose, results, and findings) and specific items (reference standards in herbal medicine, regulation of herbal medicinal products, toxicity evaluation for herbal products, quality control of herbal medicine, efficacy, adverse effects of herbal medicine, and safety of herbal medicines) (Table 1).

Data were extracted by two review authors from each article independently. As mentioned above, any disagreement was handled by consensus between the two authors or the mediation of the third author, if necessary. In the next step, a thematic analysis was done to combine similar findings $(19,20)$. Furthermore, the extracted themes were grouped for further analysis. A detailed 
Table 1. Summary of the selected articles' results based on herbal medicine

\begin{tabular}{|c|c|c|c|}
\hline Country & Study purpose & Results and finding & Reference \\
\hline USA & $\begin{array}{l}\text { A tool for rapid identification } \\
\text { of potential herbal medicine- } \\
\text { drug interactions } 2011 \text { update: } \\
\text { a review }\end{array}$ & $\begin{array}{l}\text { - } 2148 \text { references on the herbal medicines interactions published during } 2007-2010 \\
\text { were reviewed } \\
\text { - The herbal medicines interactions network allows the clinical practitioners to keep } \\
\text { themselves updated about the possible herbal medicines adverse effects based on the } \\
\text { latest information }\end{array}$ & (36) \\
\hline Malaysia & $\begin{array}{l}\text { Herbal medicine knowledge } \\
\text { base system }\end{array}$ & $\begin{array}{l}\text { - Herbal medicines knowledge platform includes four main categories of knowledge } \\
\text { that are as follows: knowledge about the plants, knowledge about the traditional } \\
\text { medicine, knowledge about processing and knowledge about pharmacology } \\
\text { - Many medicines presently available for treatment of disease have some weaknesses } \\
\text { including low efficacy due to drug-resistance, high toxicity or high cost. Such concerns, } \\
\text { consequently, have driven the commercial drug companies toward the research and } \\
\text { development of new plant-driven drugs. The herbal drugs platform would assist the } \\
\text { pharmaceutical companies in the discovery of herbal medicines }\end{array}$ & (37) \\
\hline
\end{tabular}

An automated technique to identify potential

Taiwan inappropriate traditional Chinese medicine prescriptions

Brazil Regulation of herbal medicines in Brazil

Herbal Reference Standards:

Germany applications, definitions and regulatory requirements

Herbal medicines: old and

Brazil new concepts, truths and misunderstandings

Regulation of traditional

Japan herbal medicinal products in Japan

Quality Related safety issueevidence-based validation of herbal medicine farm to pharma

The use of community herbal monographs to UK facilitate registrations and authorizations of herbal medicinal products in the European Union 2004-2012

Network Pharmacology-based approaches capture Essence of Chinese herbal medicines

Future visions for traditional and herbal medicinal

Germany Products-A global practice for evaluation and regulation?

Systems pharmacology in drug discovery and therapeutic insight for herbal medicines
As many as 1920 herbal medicines were studied. Medication errors including improper prescription of the herbal medicines may cause serious adverse effects for the patients. Applying an automatic method for identifying the potential improper prescription of the herbal medicines with a sensitivity of $97.1 \%$ is assumed to be a successful model for the automatic diagnosis of improper drug orders

Based on a cross-sectional study on 364 pregnant women in teaching hospital of Gondar in the northeast Ethiopia in 2016, 48.6\% have used herbal medicines during their pregnancy while the majority of the herbal drug consumers (89.8\%) have not consulted with their physician regarding the consumption of the herbal medicines

Herbal medicines regulations imposed by Brazil have forbidden the manufacturing, sale or supply/distribution of the herbal products (even the export products) prior to their formal registration. The herbal medicine registration is valid for 5 years and is subject to re-record every five years

The herbal healing products and food and dietary supplements must comply with the legal requirements on the production, test, storage and distribution. Compilation of reference standards for specifying the herbal medicines with complex combination is a common challenge that needs to be effectively addressed

Based on a new survey on about 1000 herbal medicines, only 156 drugs were clinically tested usable for pharmacological and treatment purposes. It is noteworthy that efficacy of $1 / 3$ of the 156 drugs was not certified in the clinical tests

- Japan's medicine guideline is known as the governing legal reference for ensuring the quality of the herbal medicines in this country.

- Data requirements for the application of herbal healing products in Japan include the test and production techniques, standards, acute, semi-acute and chronic toxicity and clinical results

Major challenges to the development and promotion of the herbal medicines are as follows: safety evaluation, quality control and providing efficient legal guidelines

By 2013, the number of traditional herbal products formally registered in the UN members with monographs on the herbal products consumption was 1015 compound products. In herbal compounds, mostly 2 to 3 drugs or herbal plants are used. EDQM supervises the quality standards in the monographs of the European drug guideline

Network pharmacological attitudes toward herbal medicines is a new research paradigm useful for transforming the experience-based medicine to evidence based medicine and accelerating the discovery of the herbal medicines based on treatment principles in traditional medicine

There is a shared attitude on the major elements of the supervisory systems on the herbal products. Principally, the safety, efficacy, quality, risk management and product evaluation on a scientific basis must be taken into account. In addition, there is consensus among the practitioners that the patients should be provided with proper information about the traditional and medical products 
Table 1. Continued

\begin{tabular}{|c|c|c|c|}
\hline Country & Study purpose & Results and finding & Reference \\
\hline China & $\begin{array}{l}\text { Community pharmacist's } \\
\text { responsibilities with regards } \\
\text { to traditional medicine/ } \\
\text { complementary medicine } \\
\text { products: A systematic } \\
\text { literature review }\end{array}$ & $\begin{array}{l}\text { A systemic pharmacological platform for the herbal medicines allows the analysis of the } \\
\text { herbs effective on the treatment of a given disease while the chemical data platform } \\
\text { would assist research on the active ingredients of the available plants. Such platform may } \\
\text { create medicine-purpose, medicine-path and medicine-patient networks and identify the } \\
\text { herbs-disease-organism interrelations }\end{array}$ & (41) \\
\hline USA & $\begin{array}{l}\text { Safety Surveillance of } \\
\text { traditional Chinese medicine: } \\
\text { current and future }\end{array}$ & $\begin{array}{l}\text { This study examined the responsibilities of the pharmacists in the safety and proper use } \\
\text { of herbal medicines that are as follows: confirming and certifying the herbal medicinal } \\
\text { products, having knowledge about the herbal medicines, ensuring the safe consumption, } \\
\text { documenting the herbal medicines use, reporting the adverse effects of the herbal drugs, } \\
\text { providing training and cooperating with other health care practitioners. }\end{array}$ & $(42)$ \\
\hline Malaysia & $\begin{array}{l}\text { Pharmacovigilance of herbal } \\
\text { medicines: Current state and } \\
\text { future directions }\end{array}$ & $\begin{array}{l}\text { Herbal medicines are commonly consumed together with other medicines. Accordingly, } \\
\text { it is necessary to monitor the possible consequences of such combined usage and control } \\
\text { any undesirable adverse }\end{array}$ & (32) \\
\hline India & $\begin{array}{l}\text { Challenges and opportunities } \\
\text { in the advancement of herbal } \\
\text { medicine: India's position and } \\
\text { role in a global context }\end{array}$ & $\begin{array}{l}\text { Lack of ecological variety, excessive exploitation, biological unlawful reproduction, non- } \\
\text { scientific usage of the herbal drugs, industrialization and lack of regulation and framework } \\
\text { have been reported to be the major barriers to the development of herbal medicines in } \\
\text { India }\end{array}$ & (3) \\
\hline USA & $\begin{array}{l}\text { Context effects in western } \\
\text { herbal medicine: fundamental } \\
\text { to effectiveness? }\end{array}$ & $\begin{array}{l}\text { Based on the qualitative studies on the herbal medicines, the patient-specialist } \\
\text { interaction, treatment environment and background effects of the herbs are among the } \\
\text { factors affecting the efficacy of the herbal medicines }\end{array}$ & (43) \\
\hline Sweden & $\begin{array}{l}\text { Requirements on efficacy of } \\
\text { herbal medicinal products }\end{array}$ & $\begin{array}{l}\text { Documentation of the usage technique of herbal medicines positively affects herbal } \\
\text { medicines safety evaluation and quality control }\end{array}$ & (28) \\
\hline Australia & $\begin{array}{l}\text { Changing the knowledge base } \\
\text { in Western herbal medicine }\end{array}$ & $\begin{array}{l}\text { The efficacy of the herbal medicines in treating specific diseases, the association between } \\
\text { the herbal combinations and medical actions and the interactions between the medicinal } \\
\text { products and medicinal herbs are among the factors influencing the health care quality in } \\
\text { the herbal medicine }\end{array}$ & (44) \\
\hline Canada & $\begin{array}{l}\text { Regulation of natural health } \\
\text { products in Canada }\end{array}$ & $\begin{array}{l}\text { In this study, the actions taken by the WHO regarding identifying the herbal medicines, } \\
\text { certifying the products certificate and imposing the agriculture-related policies were } \\
\text { mainly examined }\end{array}$ & $(45)$ \\
\hline EU & $\begin{array}{l}\text { Quality standards of the } \\
\text { European Pharmacopoeia }\end{array}$ & $\begin{array}{l}12 \% \text { of the European encyclopedia has been devoted to the herbal medicines including } \\
\text { the scientific names of the plants (species, sub-species and type), manner and } \\
\text { consumption dose }\end{array}$ & (9) \\
\hline Germany & $\begin{array}{l}\text { Challenges of safety } \\
\text { evaluation }\end{array}$ & - Quality control is another key factor affecting the efficacy of the herbal plants & (31) \\
\hline Australia & $\begin{array}{l}\text { Quality assessment of medical } \\
\text { herbs and their extracts: } \\
\text { Criteria and prerequisites for } \\
\text { consistent safety and efficacy } \\
\text { of herbal medicines }\end{array}$ & $\begin{array}{l}\text { - The main requirements for evaluating the safety of herbal medicines have been } \\
\text { illustrated in the } \mathrm{EC} / 83 / 2001 \text {. } \\
\text { - The medicinal herbs quality is an applied concept that is defined based on } \\
\text { phytochemical stability indexes }\end{array}$ & (11) \\
\hline Australia & $\begin{array}{l}\text { Evidence-based toxicity } \\
\text { evaluation and scheduling of } \\
\text { Chinese herbal medicines }\end{array}$ & Excessive usage of herbal medicines may result in reverse reactions, toxicity and/or death & (23) \\
\hline USA & $\begin{array}{l}\text { Traditional knowledge of } \\
\text { Western herbal medicine and } \\
\text { complex systems science }\end{array}$ & $\begin{array}{l}\text { Herbal medicine is based on the traditional knowledge or the common sense obtained } \\
\text { during the time through observation and real experiences }\end{array}$ & (46) \\
\hline India & $\begin{array}{l}\text { Revival, modernization } \\
\text { and integration of Indian } \\
\text { traditional herbal medicine in } \\
\text { clinical practice: importance, } \\
\text { challenges and future }\end{array}$ & $\begin{array}{l}\text { Lack of compiled and well-organized rules and instructions for controlling the medicinal } \\
\text { herbs, excessive harvest, weak agriculture techniques, weak actions before and after } \\
\text { the product harvesting are among the most common problems in the herbal medicines } \\
\text { industry }\end{array}$ & (4) \\
\hline
\end{tabular}


description of the extracted themes was presented in the results. In addition, the validity of the themes extraction process was confirmed by cross-checking the papers and discussion between the two authors (21). The last step of methodology was summarizing the selected papers and identifying the major factors. This step was completed by calculating the frequencies and percentages for the items' results.

\section{Results}

Following the methodology steps, 1532 papers were retrieved from which 27 academic papers were included in the final analysis (Figure 1). Then, all articles were summarized so as to classify them in terms of the study characteristics, including publication year (Figure 2) and country (Figure 3). Afterward, based on the analysis, the main findings of papers were thematically classified into seven subcategories as follows: reference standards in herbal medicine, regulation of herbal medicinal products, toxicity evaluation for herbal products, quality control of herbal medicine, efficacy, adverse effects of herbal medicine and safety (Table 2).

\section{Overview of study characteristics}

\section{Distribution of papers by publication year}

The distribution of academic papers by publication year regarding the impact of herbal medicines on healthcare quality and challenges is illustrated in Figure 2.

The selected articles were published during the period 2008-2017. The highest frequency (n: 8) of the papers addressing the effects of consumption of herbal medicinal products were published in 2014 .

Distribution of selected articles based on the journal indicated that Journal of Ethnopharmacology published 9 (33.37\%, highest frequency) of the papers published on the effects of consumption of herbal medicinal products.

\section{Distribution of papers by country}

The distribution of research papers on herbal medicines by country is illustrated in Figure 3. As illustrated, the following countries researched on the effects of herbal medicines on healthcare quality: USA, Malaysia, Taiwan, Ethiopia, Brazil, Germany, Japan, India, China, Canada,

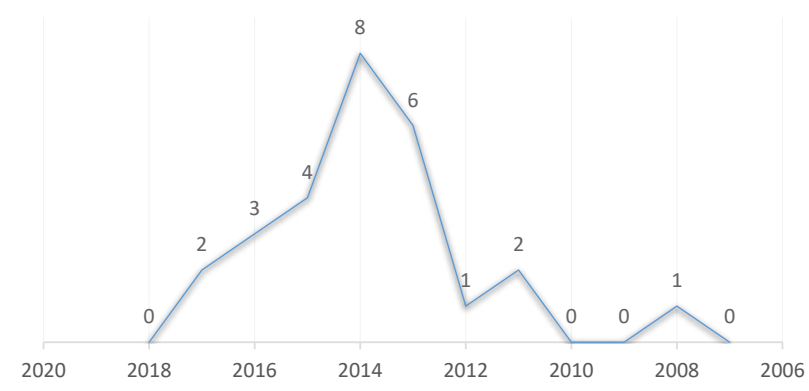

Figure 2. Distribution of articles frequency by publication year and the European Union (EU). The majority (11\%) of studies have been published in China, India and Australia (Figure 3).

\section{Distribution of papers by the extracted themes}

As per the results, from 27 papers in question, 3 (11.11\%) and $8(30 \%)$ papers cited the reference standards in herbal medicine and regulation of herbal medicinal products, respectively. Furthermore, 7 (26\%) papers made reference to toxicity evaluation in herbal products, 11 (40.75\%) to quality control of herbal medicine, $9(33.33 \%)$ to the efficacy of herbal medicine, 7 (26\%) to the adverse effects of herbal medicine, and $12(44.45 \%)$ to the safety of herbal medicine (Table 2).

\section{Discussion}

In recent years, many people use herbal medicinal products for health care promotion and therapeutic purposes either alone or combined with other drugs. Sen et al have argued that more than $60 \%$ of currently available anti-cancer drugs are derived from herbal products (4).

According to the WHO report, $80 \%$ of the people in the advanced countries meet their medical needs by herbal medicines. Economic, political, and social changes in the world have made the medical application of these natural sources/products possible for those who do not have access to the currently available varied treatment methods $(22,23)$.

Accordingly, it is essential to pay due attention in all countries to the effects of herbal medicines on the healthcare quality and identifying the involved factors. In the findings obtained from this research, seven major factors effective on the herbal medicines and their effects on the healthcare quality were examined. To confirm the quality and attributes of a newly manufactured compounds, some formal legal requirements must be satisfied. Based on the definition of chemical reference

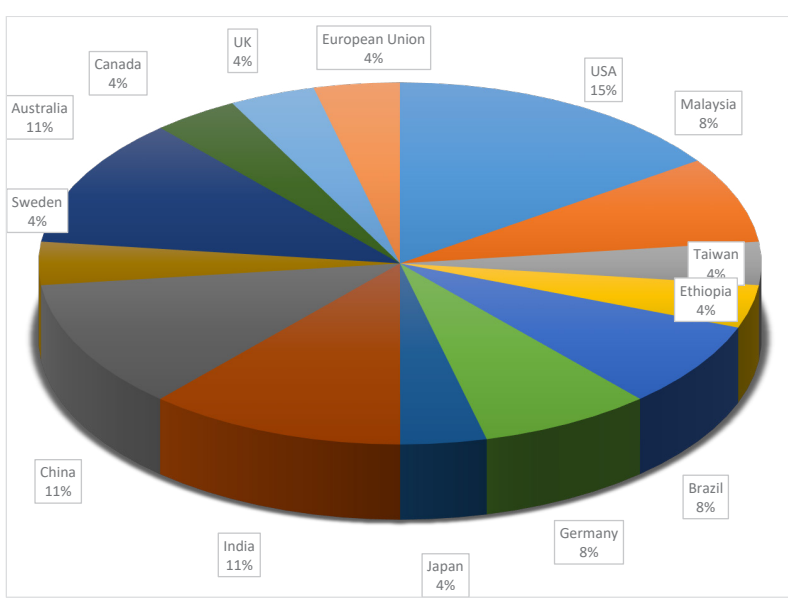

Figure 3. Distribution of frequency and percentage of selected articles related to herbal medicine by country. 
Table 2. Factors influencing the effects of herbal medicines on the health care quality in nations under study

\begin{tabular}{llll}
\hline Factors & Number = 27 & Percentage (\%) & References \\
\hline Reference standards in herbal medicine & 3 & 11.11 & $(24,27,37)$ \\
Regulation of herbal medicinal products & 8 & 30 & $(13,24,25,28,30,31,43,45)$ \\
Toxicity evaluation in herbal products & 7 & 26 & $(23,25,27,28,30,38,46)$ \\
Quality control of herbal medicine & 11 & 40.75 & $(4,7,9,11,27,31-33,39,42,44)$ \\
Efficacy in herbal medicine & 9 & 33.33 & $(3,4,11,13,25,29,33,39,40)$ \\
Adverse effects of herbal medicine & 7 & 26 & $(7,32,36,38,41,43,46)$ \\
Safety in herbal medicine & 12 & 44.45 & $(3,11,13,29,31,33,38,40-42,45,46)$ \\
\hline
\end{tabular}

substances incorporated in the European Medicine Manual published (EDQM), the primary reference standards refer to the appropriate standards for a given objective without any need to be compared with another standard currently in use for proving its appropriateness. Within the quality control framework, applying appropriate reference standards is assumed necessary to ensure the safety and efficacy of the products (24). According to the findings of this review, codification of a reference standard for each herbal medicine can provide convincing evidence on the quality control and non-toxicity of the medicine. In some nations such as China, a medicinal encyclopedia has been compiled to categorize the medicines based on toxicity index as follows: high toxic, toxic and non-toxic. Since July 2012, new reports on the toxicology of herbal medicines have been presented in Australia under the supervision of the traditional medicine physicians. Although some herbal medicines have been approved based on the standard requirements, there is no such standard for some others due to lack of sufficient research (23). During the 2010-2012 periods, as many as 81 new formulas have been added to the formal confirmatory standards in Japan. In 2013, the updated edition of the manual of the standards containing the certificates of the herbal products and medicines was published (25). In accordance with the interview results, as with many other developing countries, Iran suffers from the scarcity of such standards. Given people's lack of knowledge about the toxicity of herbal medicines, it is necessary to determine the toxicity of the drugs in the drug's monographs. Training the distributors of the medicinal herbs should also be taken under the supervision of the Food and Drug Administration.

In the EU, a sophisticated supervisory framework on herbal medicine products has been incorporated in the revised guideline European commission (EC/83/2001) and (EC/63/2003). Based on this guideline, all the herbal medicines are required to comply with the GMP (11). This guideline gives some useful insight into what information should be incorporated in the order of herbal medicine as well as its medical function (26-28). To observe the quality control standards in the herbal medicine monographs, the least information including the scientific full name of the herb, content and ingredients mentioned in the prescription order as well as the identity number of the herb must be included to be submitted to the pharmacy $(9,29)$. To promote the legal framework for the registration of the herbal medicines, Brazil's National Health Surveillance Agency (ANVISA) has certified the applied standard Resolution Directorate Collegiate (RDC $26 / 2014$ c). According to this law, prior to mass production of the herbal medicines and their distribution among the distributors, they are required to be registered. The medicines registration will be legally valid for 5 years (13). As the data from the interviews indicated, in Iran, the Food \& Drugs Administration exerts control over the procedures of production and distribution of medicinal herbs. However, there is no guideline to control either the procedure of production and distribution or the vendors of the medicinal herbs. This lack of surveillance has created numerous problems for the people, including those who are inclined to use the medicinal herbs purchased from vendors as much confidently and safely as possible.

Toxicity evaluation is considered as a highly significant and critical component in the herbal medicines. One of the methods in use for the risk analysis of the herbal medicines and their efficacy and toxicity in some nations is expressed by therapeutic index defined as the ratio LD50/ED50. LD50 reflects the consumption dose reported as being toxic in 50\% of the population while ED50 reflects the consumption dose reported as being effective in $50 \%$ of the population. Here, the goal is to represent the safety of one medicine by focusing on the ratio between the efficacy and the amount of toxin consumed. Therapeutic index is a major factor facilitating the identification of the benefit of the drugs $(15,23)$. Quality control of the chemical compounds used in the herbal products is necessary up to the clinical trial stage and the reproduction of the clinical trial (30). In some cases, wrong identification of the herb has caused wrong collection and preparation followed by the wrong formulation, leading to certain problems and challenges. Quality control is another key factor for the efficacy of herbal plants (29). A major advantage of herbal medicines is their complexity. The ingredients of herbal medicines have multiple functions. Accordingly, the efficacy of herbal medicines is higher than conventional drugs (31). Besides 
that, herbal medicines are usually consumed along with other drugs. Therefore, it is essential to be knowledgeable about the potential side effects of this combination usage and monitor all potential undesirable complications. This goal is rapidly attainable by using pharmaco-vigilance systems. To control the herbal medicines and analyze the reasons for undesirable complications, the national pharmaco-vigilance centers (or other equivalent centers) must attain the necessary specialized skills. Using standard categorization and diagnosis may be desirable for sending a report to the Uppsala Monitoring Centre (UMC). Coding of the undesirable reactions with herbal medicines must be coordinated with the coding system of other drugs. Hence, UMC has suggested using WHO-Drug Dictionary (WHO-DD). This dictionary has been compiled for storing the structural and classified information on the names of the herbal products and their ingredients as with similar information on other drugs (32). This dictionary would increase the efficacy of herbal medicines.

Considering the increased demand for the plant-driven medicines, it is necessary to provide some guarantees on the quality and safety of the herbal medicines. Regarding approaches to the applications of herbal medicines from the quality control, safety and efficacy perspective, it should be argued that traditional usage of these plants will require systematic standardization. In India, more than 2500 formulations extracted from plants are used for producing local and traditional medicines, where over 1.5 million medical consulters use traditional medicine systems for prescribing herbal medicines. Besides that, 7800 manufacturing units are operating in the field of producing the natural health products and traditional formulations extracted from the plants (9). After-sales supervision is considered as another necessary constituent of safety monitoring of herbal plants. Lack of evidence on the safety and efficacy of herbal medicines is one of the main barriers to the reliable and convenient delivery of products to the customers (33). From the interviewees' perspective, to overcome the current barriers, a global safety surveillance system should be established so as to effectively check the originality and characteristics of the herbal products and medicines. In this regard, using advanced technologies such as quality control standards during the manufacturing and processing of the herbal medicines and promoting the evidence-based traditional medicine care system would be highly effective. The herbal medicines are generally assumed to have no side effects. To put it differently, a large number of consumers regard herbal medicines as healthier than chemical drugs without any possible interactions with other herbal or chemical medicines. However, care should be taken that the irrational consumption of these medicines may create numerous problems that adversely affect patient treatment $(30,34,35)$.

Illogical usage of the medicines, lack of qualified physicians, unreliable and confusing information, lack of sufficient budget, lack of centralized marketing and commercialization, and lack of appropriate knowledge are all factors that contribute to delaying the global advancement of herbal medicines. Lack of protection of biodiversity and traditional medicinal plants is a great challenge, as well (4).

When making decisions on the necessity of pharmacological and toxicology studies, the documented adverse effects of one herb or herb blend, its respective types, and herbal combinations should be taken into account (10). In Iran, the government is required to establish national surveillance systems in different health sector levels to monitor and evaluate any possible adverse effects. Furthermore, designing such systems must be accomplished by consulting with the professionals of traditional medicine.

\section{Conclusion}

This review presented a summary of the extant literature about the effects of herbal medicine on health care quality and those involved in the production and distribution of herbal medicinal products. There are numerous factors effective on the safety and quality of the herbal medicinal products, including the toxicity rate of the herbs, environmental pollutions (such as air and soil pollution and heavy metals), agricultural activities (such as pesticides, fungi, heavy metals, microorganism and endotoxins) and processing and production management (including the storage, additives, microorganisms and endotoxins). Other safety-related issues, including the long-term toxicity, dose-dependent toxicity, continuation of treatment, herb-drug interactions, and herb-herb interactions, should also be evaluated when using herbal medicines. The main challenge faced by the majority of the herbal medicines consumers is to ensure that they are using raw, non-harmful, non-polluted herbal plants with stable quality. The increasing incidence of environmental pollution such as soils containing heavy metals is one inevitable barrier to the global acceptance of herbal medicines. To overcome all the existing challenges, various considerations should be addressed by the continued effort of the governments, training institutions, herbal industries as well as consumers.

Given the results of our review, the following recommendations can be proposed for promoting the impacts of herbal medicines on healthcare quality and dealing with related challenges:

- Monitoring the cultivation principles and focusing on the quality control infrastructures in the herbal medicines industry by respective organizations;

- Monitoring the safety principles of the herbal medicinal products usage by policymakers in the field of traditional medicine and healthcare systems;

- Codification of herbal medicine usage standards and 
monitoring on such standards;

- Communication, information and increasing the knowledge of the customers regarding the proper use of the herbal medicines based on the prescription by the traditional medicine practitioners; and

- Increasing the knowledge about the side effects of herbal medicines and negative effects of selfmedication.

\section{Acknowledgments}

We would like to express our deep and sincere gratitude to all the authors of the articles for their valuable contributions to this review study.

\section{Authors' contributions}

All the authors contributed to data collection and preparation of the manuscript. The first draft was prepared by APT. All authors read and approved the published version of the manuscript.

\section{Conflict of interests}

The authors hereby confirm that there is no conflict of interest regarding the publication of this article.

\section{Ethical considerations}

Ethical issues (including plagiarism, data fabrication, double publication etc.) have been completely observed by the authors.

\section{Funding/Support}

This article was obtained from a Ph.D. thesis (No. 1396.9321563001.IR.IUMS.FMD.REC) at Health Information Management and defended at Iran University of Medical Sciences.

\section{References}

1. Ogirima SAO. Web-based decision support system for prescription in herbal medicine. J Emerg Trends Eng Appl Sci. 2015;6(7):245-54.

2. 2.Benzie IF, Wachtel-Galor S. Herbal Medicine: Biomolecular and Clinical Aspects. 2nd ed. CRC Press; 2011.

3. Sen S, Chakraborty R, De B. Challenges and opportunities in the advancement of herbal medicine: India's position and role in a global context. J Herb Med. 2011;1(3-4):67-75. doi: 10.1016/j.hermed.2011.11.001.

4. Sen S, Chakraborty R. Revival, modernization and integration of Indian traditional herbal medicine in clinical practice: Importance, challenges and future. J Tradit Complement Med. 2017;7(2):234-44. doi: 10.1016/j. jtcme.2016.05.006.

5. World Health Organization (WHO). WHO Guidelines on Safety Monitoring of Herbal Medicines in Pharmacovigilance Systems. WHO; 2004.

6. Mafuva C, Marima-Matarira HT. Towards professionalization of traditional medicine in Zimbabwe: a comparative analysis to the South African policy on traditional medicine and the Indian ayurvedic system. Int J Herb Med. 2014;2(2 Pt C):154-61.

7. Mukherjee PK, Bahadur S, Chaudhary SK, Kar A, Mukherjee K. Chapter 1 - Quality related safety issueevidence-based validation of herbal medicine farm to pharma. In: Mukherjee PK, ed. Evidence-Based Validation of Herbal Medicine. Boston: Elsevier; 2015. p. 1-28. doi: 10.1016/b978-0-12-800874-4.00001-5.

8. Motahari Tabari N, Yousefi SS, Heydarirad G, Kardan Soraki M, Habibipour P. Exercise from the perspective of Iranian traditional medicine. J Evid Based Complementary Altern Med. 2017;22(2):344-6. doi: 10.1177/2156587216660396.

9. Bouin AS, Wierer M. Quality standards of the European Pharmacopoeia. J Ethnopharmacol. 2014;158 Pt B:454-7. doi: 10.1016/j.jep.2014.07.020.

10. World Health Organization (WHO). WHO General Guidelines for Methodologies on Research and Evaluation of Traditional Medicine. Geneva: WHO; 2000.

11. Govindaraghavan S, Sucher NJ. Quality assessment of medicinal herbs and their extracts: criteria and prerequisites for consistent safety and efficacy of herbal medicines. Epilepsy Behav. 2015;52(Pt B):363-71. doi: 10.1016/j. yebeh.2015.03.004.

12. Ansani NT, Ciliberto NC, Freedy T. Hospital policies regarding herbal medicines. Am J Health Syst Pharm. 2003;60(4):367-70. doi: 10.1093/ajhp/60.4.367.

13. Carvalho AC, Ramalho LS, Marques RF, Perfeito JP. Regulation of herbal medicines in Brazil. J Ethnopharmacol. 2014;158 Pt B:503-6. doi: 10.1016/j.jep.2014.08.019.

14. Iran Traditional Medicine Association. [updated Dec 2, 2016; cited 2017 Feb 10]. Available from: https://itma.ir/.

15. 15.Nessabian S, Gholamhosseni T, Jabalameli F. Comparison of Iran's medicinal plants exporting comparative advantage with other exporting countries (case study: Fennel, Badian, Anise and Corian). Econ Model. 2013;6(4):75-92.

16. Moher D, Liberati A, Tetzlaff J, Altman DG. Preferred reporting items for systematic reviews and meta-analyses: the PRISMA statement. Ann Intern Med. 2009;151(4):2649. doi: 10.7326/0003-4819-151-4-200908180-00135.

17. Pluye P, Robert E, Cargo M, Bartlett G, O'Cathain A, Griffiths F, et al. Proposal: A Mixed Methods Appraisal Tool for Systematic Mixed Studies Reviews. Montréal: McGill University. 2011.

18. Akhlaq A, McKinstry B, Muhammad KB, Sheikh A. Barriers and facilitators to health information exchange in low- and middle-income country settings: a systematic review. Health Policy Plan. 2016;31(9):1310-25. doi: 10.1093/heapol/czw056.

19. Lucas PJ, Baird J, Arai L, Law C, Roberts HM. Worked examples of alternative methods for the synthesis of qualitative and quantitative research in systematic reviews. BMC Med Res Methodol. 2007;7:4. doi: 10.1186/14712288-7-4.

20. van Panhuis WG, Paul P, Emerson C, Grefenstette J, Wilder $\mathrm{R}$, Herbst AJ, et al. A systematic review of barriers to data sharing in public health. BMC Public Health. 2014;14:1144. doi: 10.1186/1471-2458-14-1144.

21. Salahuddin L, Ismail Z. Classification of antecedents towards safety use of health information technology: a systematic review. Int J Med Inform. 2015;84(11):877-91. 
doi: $\quad$ 10.1016/j.ijmedinf.2015.07.004.

22. Bonifácio BV, Silva PB, Ramos MA, Negri KM, Bauab TM, Chorilli M. Nanotechnology-based drug delivery systems and herbal medicines: a review. Int J Nanomedicine. 2014;9:1-15. doi: 10.2147/ijn.s52634.

23. Kim EJ, Chen Y, Huang JQ, Li KM, Razmovski-Naumovski $\mathrm{V}$, Poon J, et al. Evidence-based toxicity evaluation and scheduling of Chinese herbal medicines. J Ethnopharmacol. 2013;146(1):40-61. doi: 10.1016/j.jep.2012.12.027.

24. Zöllner T, Schwarz M. Herbal reference standards: applications, definitions and regulatory requirements. Rev Bras Farmacogn. 2013;23(1):1-21. doi: 10.1590/s0102$695 \times 2012005000144$.

25. Maegawa H, Nakamura T, Saito K. Regulation of traditional herbal medicinal products in Japan. J Ethnopharmacol. 2014;158 Pt B:511-5. doi: 10.1016/j.jep.2014.07.012.

26. Kroes BH. The legal framework governing the quality of (traditional) herbal medicinal products in the European Union. J Ethnopharmacol. 2014;158 Pt B:449-53. doi: 10.1016/j.jep.2014.07.044.

27. Peschel W. The use of community herbal monographs to facilitate registrations and authorisations of herbal medicinal products in the European Union 2004-2012. J Ethnopharmacol. 2014;158 Pt B:471-86. doi: 10.1016/j. jep.2014.07.015.

28. Claeson P. Requirements on efficacy of herbal medicinal products. J Ethnopharmacol. 2014;158 Pt B:463-6. doi: 10.1016/j.jep.2014.07.017.

29. Wiesner J. Challenges of safety evaluation. J Ethnopharmacol. 2014;158 Pt B:467-70. doi: 10.1016/j. jep.2014.08.013.

30. Wiesner J, Knöss W. Future visions for traditional and herbal medicinal products--a global practice for evaluation and regulation? J Ethnopharmacol. 2014;158 Pt B:516-8. doi: $10.1016 /$ j.jep.2014.08.015.

31. Carmona F, Pereira AMS. Herbal medicines: old and new concepts, truths and misunderstandings. Rev Bras Farmacogn. 2013;23(2):379-85. doi: 10.1590/s0102$695 \times 2013005000018$.

32. Shetti S, Kumar CD, Sriwastava NK, Sharma IP. Pharmacovigilance of herbal medicines: current state and future directions. Pharmacogn Mag. 2011;7(25):69-73. doi: 10.4103/0973-1296.75905.

33. Ung COL, Harnett J, Hu H. Community pharmacist's responsibilities with regards to traditional medicine/ complementary medicine products: a systematic literature review. Res Social Adm Pharm. 2017;13(4):686-716. doi: 10.1016/j.sapharm.2016.08.001.

34. Owens C, Baergen R, Puckett D. Online sources of herbal product information. Am J Med. 2014;127(2):109-15. doi: 10.1016/j.amjmed.2013.09.016.

35. Wang JF, Zhou H, Han LY, Chen X, Chen YZ, Cao ZW. Traditional Chinese medicine information database. Clin Pharmacol Ther. 2005;78(1):92-3. doi: 10.1016/j. clpt.2005.03.010.

36. Girard L, Kutt A, Necyk C, Jasser S, Law B, Filipelli A, et al. P05.32. A tool for rapid identification of potential herbal medicine-drug interactions 2011 update: a review. BMC Complement Altern Med. 2012;12(Suppl 1):P392. doi: 10.1186/1472-6882-12-S1-P392.

37. Mustaffa S, Ishak RZ, Lee C, Lim S, Sintoh M, Selan NE. Herbal medicine knowledge base system. Agricultural Ontology Service (AOS) Workshop; 2012.

38. Yang HC, Iqbal U, Nguyen PA, Lin SH, Huang CW, Jian WS, et al. An automated technique to identify potential inappropriate traditional Chinese medicine (TCM) prescriptions. Pharmacoepidemiol Drug Saf. 2016;25(4):422-30. doi: 10.1002/pds.3976.

39. Mekuria AB, Erku DA, Gebresillassie BM, Birru EM, Tizazu B, Ahmedin A. Prevalence and associated factors of herbal medicine use among pregnant women on antenatal care follow-up at University of Gondar referral and teaching hospital, Ethiopia: a cross-sectional study. BMC Complement Altern Med. 2017;17(1):86. doi: 10.1186/ s12906-017-1608-4.

40. Zhang YQ, Mao X, Guo QY, Lin N, Li S. Network pharmacology-based approaches capture essence of Chinese herbal medicines. Chin Herb Med. 2016;8(2):10716. doi: 10.1016/s1674-6384(16)60018-7.

41. Huang C, Zheng C, Li Y, Wang Y, Lu A, Yang L. Systems pharmacology in drug discovery and therapeutic insight for herbal medicines. Brief Bioinform. 2014;15(5):710-33. doi: 10.1093/bib/bbt035.

42. Liu SH, Chuang WC, Lam W, Jiang Z, Cheng YC. Safety surveillance of traditional Chinese medicine: current and future. Drug Saf. 2015;38(2):117-28. doi: 10.1007/s40264014-0250-z.

43. Snow J. Context effects in Western herbal medicine: fundamental to effectiveness? Explore (NY). 2016;12(1):5562. doi: 10.1016/j.explore.2015.10.004.

44. Evans S. Changing the knowledge base in Western herbal medicine. Soc Sci Med. 2008;67(12):2098-106. doi: 10.1016/j.socscimed.2008.09.046.

45. Smith A, Jogalekar S, Gibson A. Regulation of natural health products in Canada. J Ethnopharmacol. 2014;158 Pt B:507-10. doi: 10.1016/j.jep.2014.06.037.

46. Niemeyer K, Bell IR, Koithan M. Traditional knowledge of Western herbal medicine and complex systems science. J Herb Med. 2013;3(3):112-9. doi: 10.1016/j. hermed.2013.03.001. 